\title{
Decrease in Prostate Cancer Testing Following the US Preventive Services Task Force (USPSTF) Recommendations
}

\author{
Jun Li, MD, PhD, Zahava Berkowitz, MSPH, MSc, and Ingrid J. Hall, PhD, MPH
}

Purpose: To assess changes of prostate-specific antigen (PSA) testing following recent US Preventive Services Task Force (USPSTF) prostate cancer screening recommendations using 2005 to 2013 National Health Interview Survey data.

Methods: We calculated the percentage of PSA testing among men $\geq 40$ years by age group and ageadjusted race for each survey year. Differences between years were assessed with linear contrasts after combining all years' data.

Results: The overall percentage of PSA testing was highest in 2008 and decreased significantly in 2013. Compared with 2008 , each age group had significantly lower screening percentages in 2013 , especially men $\geq 75$ years old $(-14.0 \%$ points; $P<.001)$. Both men aged 50 to 74 and men aged $\geq 75$ had significantly lower percentages in 2013 than in 2010. For white and black men, the PSA testing percentages were highest in 2008 and decreased significantly in 2013. Only white men had a significantly lower percentage in 2013 than in 2010.

Conclusions: Significant declines in PSA testing from 2008 to 2013 in men $\geq 75$ years old may reflect the impact of the 2008 USPSTF recommendations. While the cause of the decreases in PSA testing between 2010 and 2013 among men aged 50 to 74 years old and white men is unknown, the decreases may suggest the early effects of the 2012 recommendations. (J Am Board Fam Med 2015;28:491-493.)

Keywords: Cancer Screening, Prostate Cancer, Prostate-Specific Antigen

Prostate-specific antigen (PSA) testing for prostate cancer screening has been widely used in the United States in the past 3 decades. Because harms outweighed benefits, in 2012 the US Preventive Services Task Force (USPSTF) expanded its 2008 recommendation against PSA testing among men aged $\geq 75$ years to include men of all ages. ${ }^{1}$ Trans-

This article was externally peer reviewed.

Submitted 11 February 2015; revised 7 April 2015; accepted 13 April 2015.

From the Division of Cancer Prevention and Control, National Center for Chronic Disease Prevention and Health Promotion, Centers for Disease Control and Prevention, Atlanta, GA.

Funding: none.

Conflict of interest: none declared.

Disclaimer: The findings and conclusions in this report are those of the authors and do not necessarily represent the official position of the Centers for Disease Control and Prevention.

Corresponding author: Jun $\mathrm{Li}, \mathrm{MD}, \mathrm{PhD}$, Division of Cancer Prevention and Control, Centers for Disease Control and Prevention, 4770 Buford Hwy, Mail Stop F-76, Atlanta, GA, 30341 (E-mail: ffa2@cdc.gov). lation of the USPSTF recommendations into practice has had to compete with different recommendations from many medical organizations (http:// www.guideline.gov/). Men often receive messages about screening that differ from the USPSTF recommendations. Recent studies have shown conflicting results about the impact of the 2008 USPSTF recommendations on the pattern of PSA testing. ${ }^{2-4}$ We examined National Health Interview Survey (NHIS) data from 2005 to 2013 to assess patterns of PSA testing following recent USPSTF recommendations.

\section{Methods}

The NHIS is an annual, in-person, cross-sectional survey that monitors health trends (http://www. cdc.gov/nchs/nhis.htm). The final response rates for the adult samples in 2005, 2008, 2010, and 2013 were $69.0 \%, 62.6 \%, 60.8 \%$, and $61.2 \%$, respectively. We calculated the percentage of PSA testing for each survey year by age group and age-adjusted race 
Figure 1. Percentage of prostate-specific antigen testing within the past year, by age and year, among men aged $\geq 40$ years, based on National Health Interview Survey 2005 to 2013 data. Percentages are weighted to the noninstitutionalized male population.

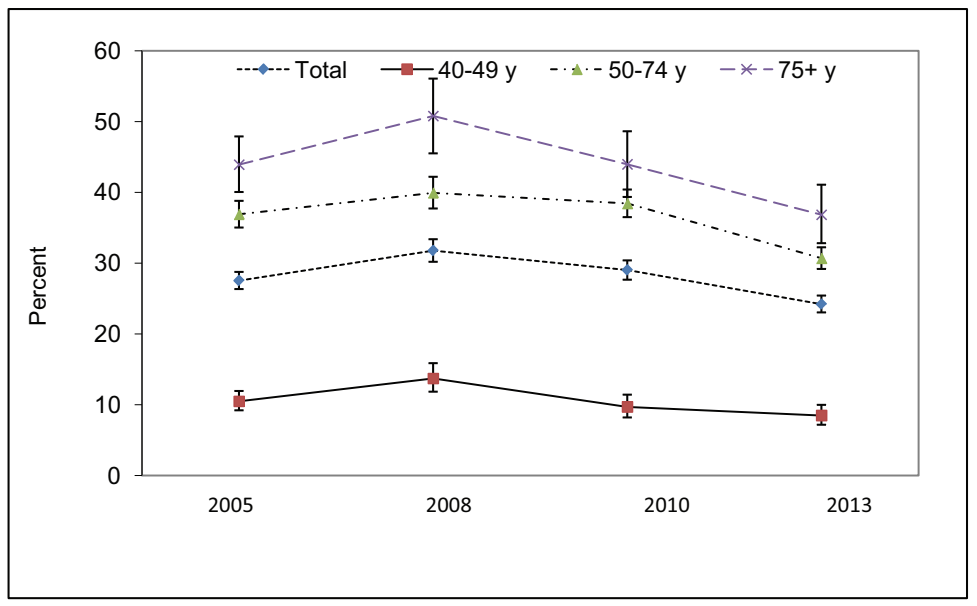

among men $\geq 40$ years who had no history of prostate cancer and who had a PSA test during a routine examination. Differences between years were assessed with linear contrasts after combining data from all survey years. All analyses were performed using SUDAAN 10 software (RTI International, Research Triangle Park, NC) to account for the complex sampling design. A $P$ value $<.05$ was considered significant.

\section{Results}

As shown in Figure 1, the overall percentage of PSA testing was highest in 2008 (31.8\%) and de- creased significantly in 2013 (24.2\%). Men $\geq 75$ years old had the highest testing percentage over the entire period. Compared with 2008, a significant reduction in PSA testing was observed in 2013 for each age group, especially for men $\geq 75$ years old $(-14.0 \%$ points; $P<.001)$. Compared with 2010, significant reductions occurred in 2013 among both men 50 to 74 and those $\geq 75$ years old.

Figure 2 shows that, for white and black men, the percentages of PSA testing were highest in $2008(33.6 \%$ and $31.1 \%$, respectively) and decreased significantly in $2013(24.7 \%$ and $23.4 \%$,

Figure 2. Percentage of prostate-specific antigen testing within the past year, by race and year, among men aged $\geq 40$ years and older, based on National Health Interview Survey 2005 to 2013 data. Percentages of race are ageadjusted to the 2010 US standard population and are weighted to the noninstitutionalized male population. American Indians and Alaska Natives are not presented because of the small sample sizes. API, Asian/Pacific Islander.

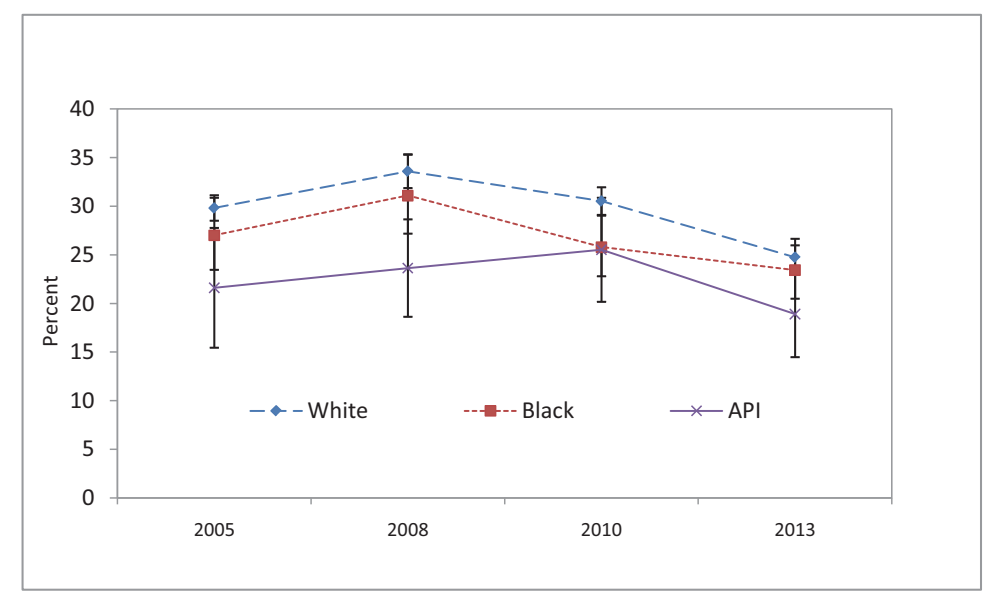


respectively). Compared with 2008, no significant reduction was observed among Asian and Pacific Islander men in 2013. Only white men had a significant decrease in PSA testing between 2010 and 2013.

\section{Discussion}

After an increase in PSA testing from 2005 to 2008 , we observed a significant decrease from 2008 to 2013. Despite the decrease, men $\geq 75$ years old continued to have the highest testing percentage from 2005 to 2013. Significant declines in PSA testing from 2008 to 2013 in men $\geq 75$ may reflect the impact of the 2008 USPSTF recommendations. While the cause of the decrease in PSA testing among men aged 50 to 74 between 2010 and 2013 is unknown, the decrease may suggest early impacts of the 2012 recommendations. A recently published study, which compared use of PSA testing 6 months before and after the 2012 recommendations, showed continuing decreases in PSA testing after the recommendation. ${ }^{5}$

White men had a significantly lower percentage of PSA testing in 2013 than in 2008 or 2010 . No significant decrease in PSA testing between 2010 and 2013 was observed among black men. Higher risk perception among black men may partially account for the slow decline in PSA testing. Reasons for stable PSA testing percentage over time among Asian and Pacific Islander men merit further investigation. Although some decrease in PSA testing has occurred in white men and men $\geq 75$ since 2008, considerable work remains to be done if the goal is to fully implement the 2008 and 2012 USPSTF recommendations in practice.

Limitations of our study include reliance or selfreported data for PSA testing and possibly selection bias related to response rates.

\section{Conclusion}

Our study reports a decrease in self-reported receipt of the PSA test following past USPSTF recommendations advising against the test. Results suggest that the recommendations may be impacting test use, especially among older men and white men.

\section{References}

1. Moyer VA; US Preventive Services Task Force. Screening for prostate cancer: U.S. Preventive Services Task Force recommendation statement. Ann Intern Med 2012;157:120-34.

2. Drazer MW, Prasad SM, Huo D, et al. National trends in prostate cancer screening among older American men with limited 9-year life expectancies: evidence of an increased need for shared decision making. Cancer 2014;120:1491-8.

3. Howard DH, Tangka FK, Guy GP, et al. Prostate cancer screening in men ages 75 and older fell by 8 percentage points after Task Force recommendation. Health Aff (Millwood) 2013;32:596-602.

4. Li J, Berkowitz Z, Richards TB, et al. Shared decision making in prostate-specific antigen testing with men older than 70 years. J Am Board Fam Med 2013;26: 401-8.

5. Cohn JA, Wang CE, Lakeman JC, et al. Primary care physician PSA screening practices before and after the final U.S. Preventive Services Task Force recommendation. Urol Oncol 2014;32:41.e23-30. 